\title{
Study on the Seismic Performance of Strengthened Reinforced Concrete Columns Based on the Experiment
}

\author{
Yanhua Sun and Xiaohu Zhang $(1)$ \\ School of Civil Engineering, Guizhou University of Engineering Science, Bijie 551700, China \\ Correspondence should be addressed to Xiaohu Zhang; zhangxiaohucumtb@163.com
}

Received 3 December 2020; Revised 20 December 2020; Accepted 26 December 2020; Published 7 January 2021

Academic Editor: Feng Xiong

Copyright (c) 2021 Yanhua Sun and Xiaohu Zhang. This is an open access article distributed under the Creative Commons Attribution License, which permits unrestricted use, distribution, and reproduction in any medium, provided the original work is properly cited.

\begin{abstract}
The seismic performance of reinforced concrete (RC) columns strengthened using steel bar/wire mesh mortar (SWM) was investigated. A comparative experimental study was performed by taking nine RC square columns strengthened with SWM and steel bar mat mortar (SM) under pseudostatic test. The effects of strengthening method and test parameters on the seismic bearing capacity, ductile deformation, and failure mode of all columns were tested and analyzed. The results show that SWMstrengthened columns can experience more cyclic loading times before the failure than SM-strengthened columns under the same axial load ratio, and the energy dissipation capacity and seismic bearing capacity of SWM-strengthened columns were higher on average than that of SM-strengthened columns by $62.3 \%$ and $73.66 \%$, respectively, proving that the strengthening method has a good application in engineering practice.
\end{abstract}

\section{Introduction}

The seismic performance of the bottom column in the frame structure directly affects the collapse resistance of the overall structure. However, many reinforced concrete (RC) columns that have been in service for a long time are insufficient in resisting earthquakes. In order to ensure the safety of people's lives and property, effective strengthening measures must be taken to improve the seismic resistance of these columns. In the numerous strengthening methods of columns, the columns are basically wrapped with appropriate building materials and then tested and studied.

Columns wrapped with ferrocement as a strengthening method have been widely studied by many agencies and researchers [1-8]. Ferrocement has been proved to be an effective RC column strengthening material with certain advantages in surface crack control and durability. However, the reinforcement ratio of the columns cannot be improved effectively by this strengthening method due to the wire mesh is too thin, and the increase of the bearing capacity of the strengthened columns is limited.
To solve the problem of insufficient bearing capacity of columns, Shang et al. [9] used small-diameter steel bar mat mortar (SM) to strengthen the columns and carried out study. The results show that the bearing capacity of the SM-strengthened column can be improved effectively, but the ductile displacement is not as large as expected. Based on the above research, it may be a feasible method to use steel bar/wire mesh mortar (SWM) to strengthen the column and improve its seismic performance.

In this study, the strengthening method of using SWM is intended to improve the ability of the column to resist earthquake damage by increasing the secondary reinforcement ratio of the column and making the concrete in the column under three-direction compression. The influence of test parameters on bearing capacity, ductile deformation, and hysteresis characteristics of nine columns was analyzed in detail.

\section{Experimental Program}

2.1. Materials. Like most of the existing columns, the concrete with strength grade of C30 was selected in this research. 
Table 1: Properties of steels.

\begin{tabular}{lcccc}
\hline Steels & $\begin{array}{c}\Phi \\
(\mathrm{mm})\end{array}$ & $\begin{array}{c}f_{y} \\
(\mathrm{MPa})\end{array}$ & $\begin{array}{c}f_{u} \\
(\mathrm{MPa})\end{array}$ & $\begin{array}{c}E_{s} \\
(\mathrm{GPa})\end{array}$ \\
\hline Wire mesh ${ }^{*}$ & 1.2 & 403 & 502 & 207 \\
Stirrup/strengthening & 6 & 403 & 502 & 210 \\
$\begin{array}{l}\text { Strengthening } \\
\begin{array}{l}\text { Longitudinal } \\
\text { reinforcement }\end{array}\end{array}$ & 10 & 370 & 631 & 210 \\
\hline
\end{tabular}

Note: the grid spacing of the steel wire mesh is $11 \mathrm{~mm} \times 11 \mathrm{~mm}$.

The concrete was made of ordinary Portland cement, crushed stone, river sand, and tap water. The maximum diameter of crushed stone was $20 \mathrm{~mm}$. The modulus fineness of river sand was 2.98. All kinds of concrete preparation materials meet the requirements of American standard ACI Committee 318 [10].

In the process of column pouring, the standard concrete cube test block was made and cured under the same conditions as the column. After 28 days of curing, the average cube strength was $45.0 \mathrm{MPa}$. In the process of column reinforcement, the standard mortar test block was made and its average cube strength was $48.8 \mathrm{MPa}$ after 28 days of curing. The mechanical properties of the concrete and mortar meet the requirements of GB50010-2010 [11]. The mechanical properties of steels are listed in Table 1.

2.2. Production of RC Columns. According to the experimental scheme, nine square columns were made. As shown in Figure 1, each column had a clear height of $1100 \mathrm{~mm}$. Before the column was strengthened, its section size was $180 \mathrm{~mm}$ $\times 180 \mathrm{~mm}$. All the columns were constructed using 4 longitudinal reinforcements with a diameter of $12 \mathrm{~mm}$. Stirrups of nine columns were arranged with a diameter of $6 \mathrm{~mm}$ and spacing of $150 \mathrm{~mm}$. In order to ensure the safety of the test and simulate the real working condition of the column, each column was set with a footing of $1100 \mathrm{~mm} \times 340 \mathrm{~mm}$ $\times 280 \mathrm{~mm}$.

2.3. Strengthening Process. In order to enhance the bonding force of the interface, the surface of column was polished and cleaned before strengthening. Then, the surface of column was washed, and a layer of interface agent is coated on the column surface after drying. The whole strengthening process followed the guidance of ACI Committee 549 (1999) [1]. For SM-strengthened columns, four steel bars with diameter of $12 \mathrm{~mm}$ were added at the four corners of the column, which were welded together with $6 \mathrm{~mm}$ diameter stirrups at a spacing of $100 \mathrm{~mm}$. For SWMstrengthened columns, the steel wire mesh was wrapped outside the steel bar mat. Finally, the repair cement mortar was plastered after applying steel bar/wire mesh. After strengthening, the section size of the columns became $210 \mathrm{~mm} \times 210 \mathrm{~mm}$. All the strengthened columns were cured for a sufficient time before loading test. Typical strengthening details for the columns are shown in Figure 2.

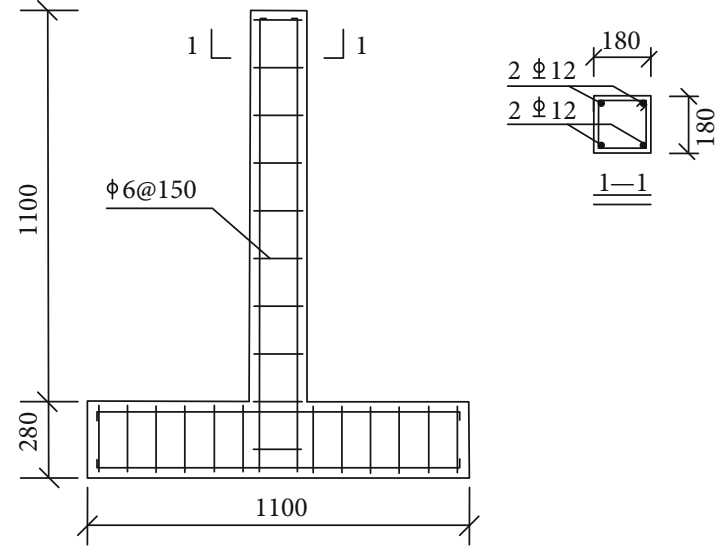

FIGURE 1: Design size of column (mm).

2.4. Classification of Specimens. The properties of all columns are listed in Table 2. Column $\mathrm{O}$ without any strengthening measures was used to compare the test data (Figures 2(a) and 2(f), Table 2). SM-strengthened columns were strengthened only with a steel bar mat (Figures 2(b) and 2(g), Table 2). SWM-strengthened columns were strengthened with steel wire mesh of different wraps include a steel bar mat. The meaning of the number 1 in SWM1 is that one wrap of wire mesh was used for strengthening column except for a steel bar mat (Figures 2(c) and 2(h), Table 2). The meaning of the number 2 in SWM2 is that two wraps of wire mesh were used for strengthening column except for a steel bar mat (Figures 2(d) and 2(i), Table 2). The meaning of the number 0.5 in SWM0.5 is that one wrap of wire mesh was used for strengthening column except for a steel bar mat, and the wire mesh was set from the middle point to the bottom of the column (Figures 2(e) and 2(j), Table 2).

2.5. Test Devices and Methods. The experiment was carried out in the structural engineering experimental center of Shantou University. The footing of column was firmly fixed on the rigid ground to ensure that there was no horizontal displacement at the bottom of the footing of column during the test. Firstly, the vertical load is applied to the top of the column by a $1000 \mathrm{kN}$ hydraulic jack to the control value. For example, when the axial load ratio control value of the column is 0.33 , the jack loading value is $208.11 \mathrm{kN}$. Then, the lateral low-cycle repeated load is applied at the loading point of the column top through MTS actuator fixed on the reaction wall. The test device is shown in Figure 3.

A typical loading regime is shown in Figure 4. Before yielding, the column was loaded by force control method, and each stage of load cycle was once. After yielding, the column was loaded by displacement control method, and each stage of load cycle was 3 times. In Figure $4, \Delta_{0}$ is the theoretical yield displacement of a test column. In each stage of loading process, the push force applied to the 


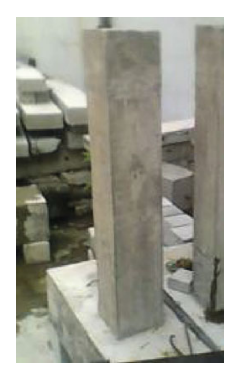

(a) $\mathrm{O}$

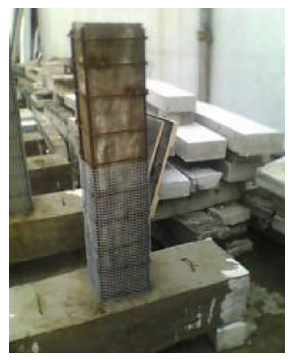

(e) SWM0.5

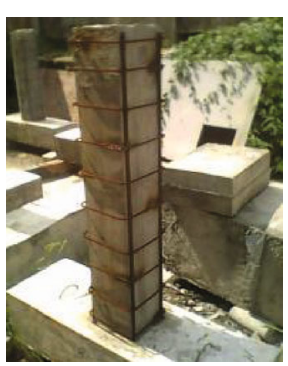

(b) SM

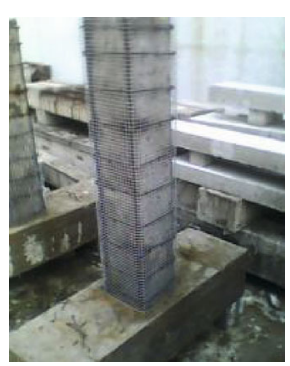

(c) SWM1

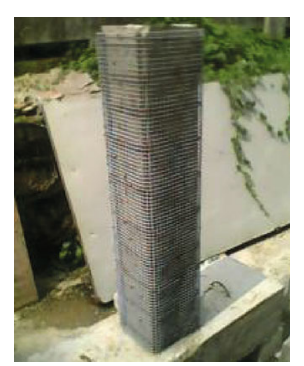

(d) SWM2

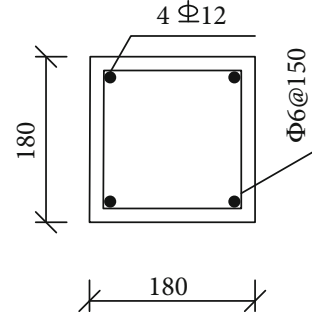

(f) Cross section of $\mathrm{O}$

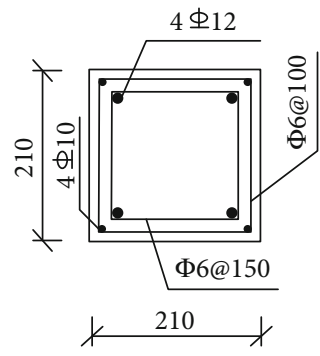

(g) Cross section of SM

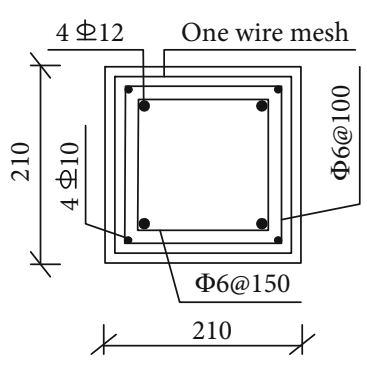

(h) Cross section of SWM1

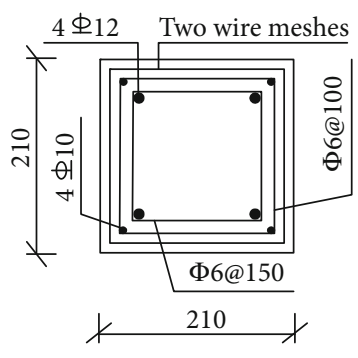

(i) Cross section of SWM2

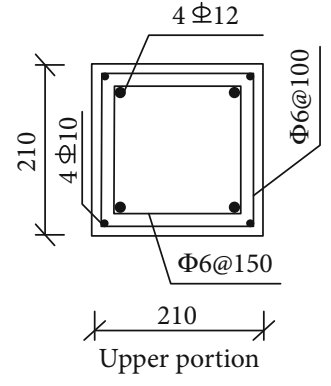

(j) Cross section of SWM0.5

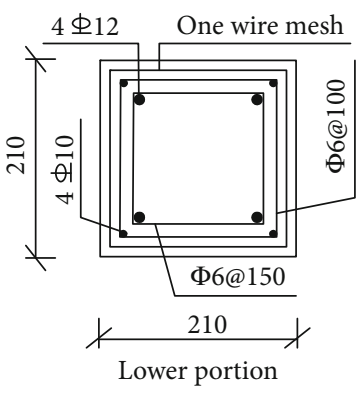

FIGURE 2: Strengthening details of columns.

column was regarded as the forward cycle, and the pull force applied to the column was regarded as the reverse cycle. When the bearing capacity of the column decreased to $85 \%$ of the peak load, the column was considered to be damaged, and the test was stopped.

\section{Results and Discussion}

3.1. Crack Patterns and Failure Modes. The failure process of the nine columns was similar, and all the nine columns failed in bending in the later stage of the test. The crack patterns of typical columns are shown in Figure 5.

For column $\mathrm{O}$, at the beginning of applying lateral load, there was no crack because the deformation of the column was in the range of elastic deformation. When the longitudinal bars of the column yielded, the first horizontal bending crack appeared at the bottom of the column. With the increase of loading displacement at the top of the column, new cracks appeared gradually in the plastic hinge area of columns, and the existing cracks extended and widen. With the further increase of loading displacement at the top of the column, one of the main horizontal cracks at the bottom of the column was penetrated, and the degree of concrete crushing in the com-
TABle 2: Properties of columns.

\begin{tabular}{|c|c|c|c|c|}
\hline \multirow{2}{*}{$\begin{array}{l}\text { Column } \\
\text { series }\end{array}$} & \multirow[t]{2}{*}{ Number } & \multirow{2}{*}{$\begin{array}{l}\text { Strengthening } \\
\text { method }\end{array}$} & \multicolumn{2}{|c|}{$\begin{array}{c}\text { Longitudinal } \\
\text { reinforcement ratio } \\
(\%)\end{array}$} \\
\hline & & & $\begin{array}{l}\text { Steel } \\
\text { bar }\end{array}$ & $\begin{array}{l}\text { Wire } \\
\text { mesh }\end{array}$ \\
\hline $\mathrm{O}$ & 1 & - & 1.63 & - \\
\hline SM & 2 & SM & 2.72 & - \\
\hline SWM1 & 2 & SWM & 2.72 & 0.20 \\
\hline SWM2 & 2 & SWM & 2.72 & 0.40 \\
\hline SWM0.5 & 2 & SWM & 2.72 & 0.20 \\
\hline
\end{tabular}

pression area was intensified, and slag falling occurred. When the loading displacement at the top of the column reached $11.9 \mathrm{~mm}$, the longitudinal bars at the cracks were exposed and bent, and the bearing capacity of the column began to decrease. When the loading displacement at the top of the column reached $21.2 \mathrm{~mm}$, the lateral force of the column was lower than $85 \%$ of the peak lateral force, and the test was stopped. The failure pattern of column $\mathrm{O}$ is shown in Figure 5(a). 


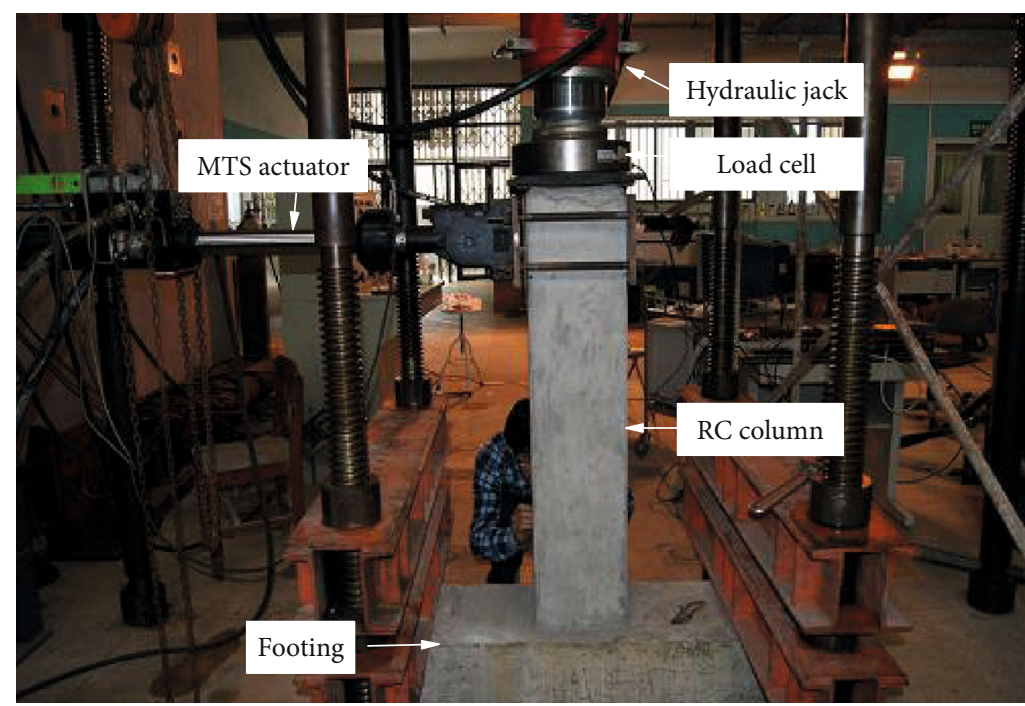

Figure 3: Column test setup.

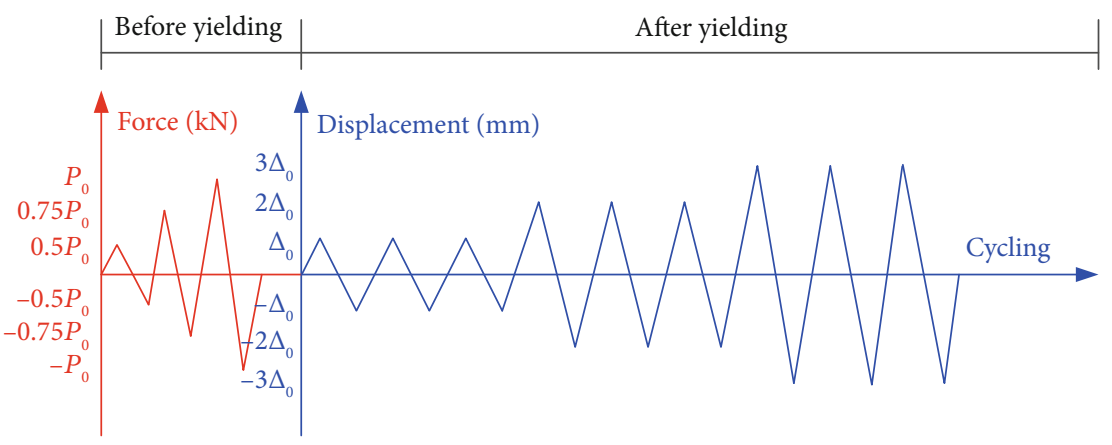

FIgURE 4: Loading regime.

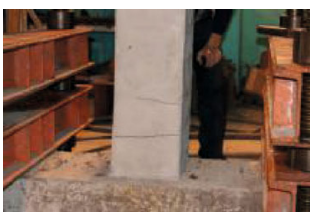

(a) $\mathrm{O}$

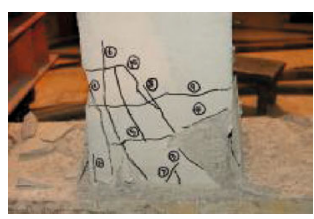

(c) SWM1-2

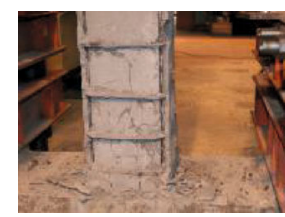

(b) SM-2

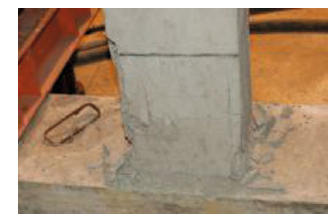

(d) SWM2-2

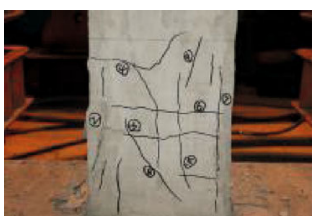

(e) SWM0.5-1

FIGURE 5: Failure patterns of columns. 


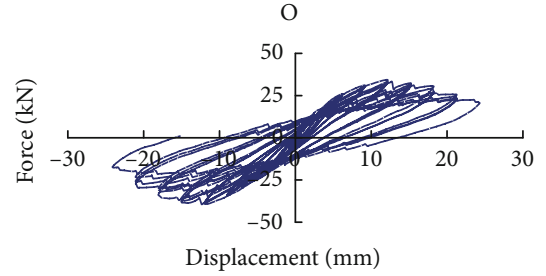

SWM2-1

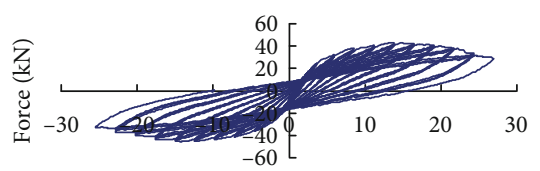

Displacement $(\mathrm{mm})$

SWM1-2

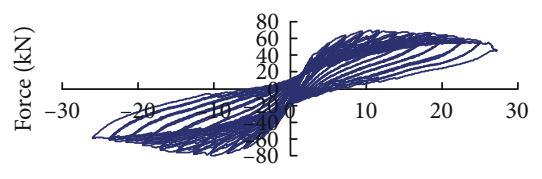

Displacement (mm)
SM-1

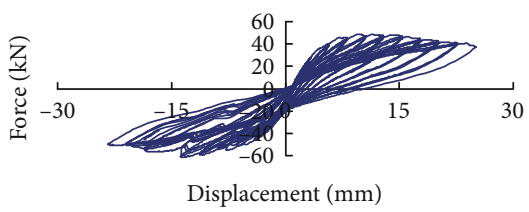

SWM0.5-1

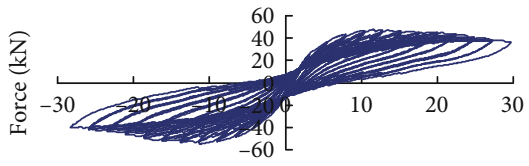

Displacement (mm)

SWM2-2

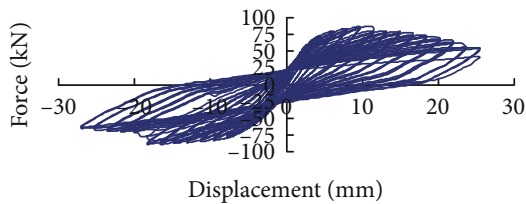

Displacement (mm)
SWM1-1

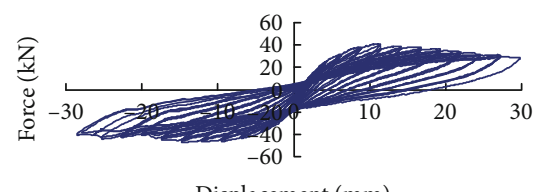

Displacement (mm)

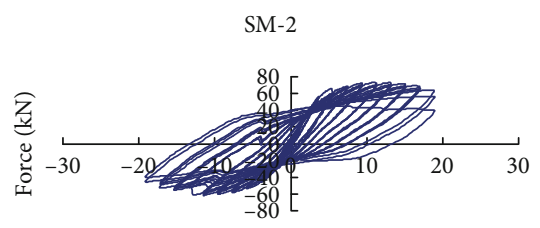

Displacement (mm)

SWM0.5-2

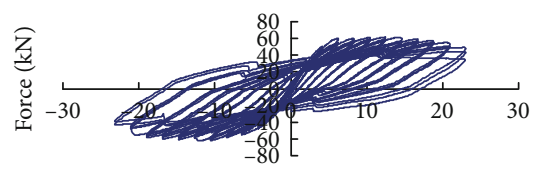

Displacement (mm)

Figure 6: Hysteresis loops of columns.

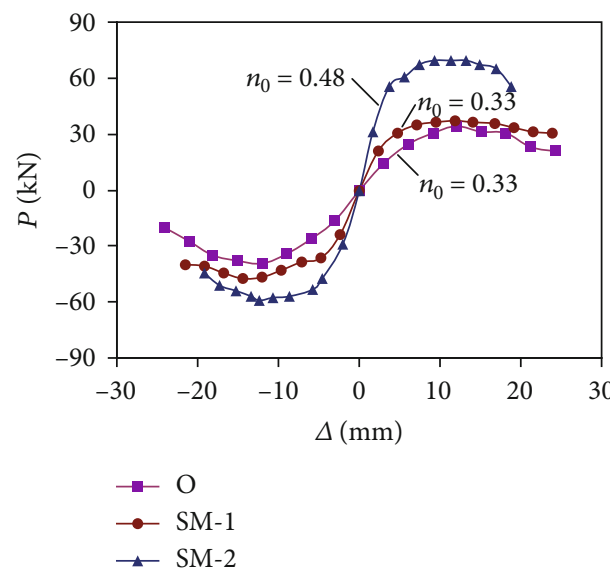

(a)

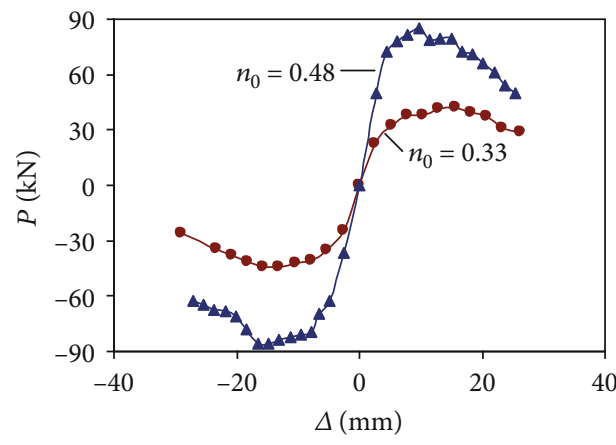

$\rightarrow$ SWM2-1
$\rightarrow$ SWM2-2

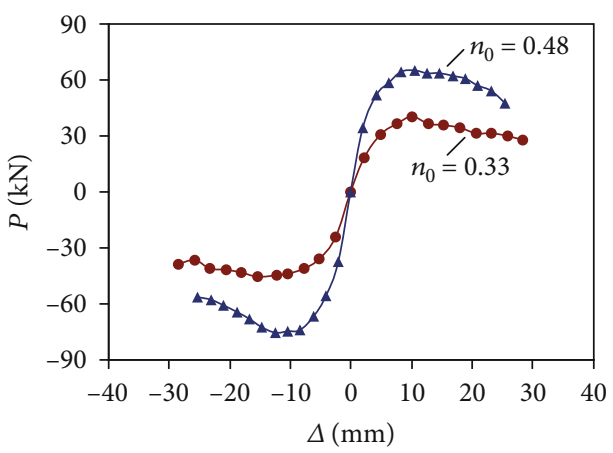

$\longrightarrow$ SWM1-1

$\rightarrow$ SWM1-2

(b)

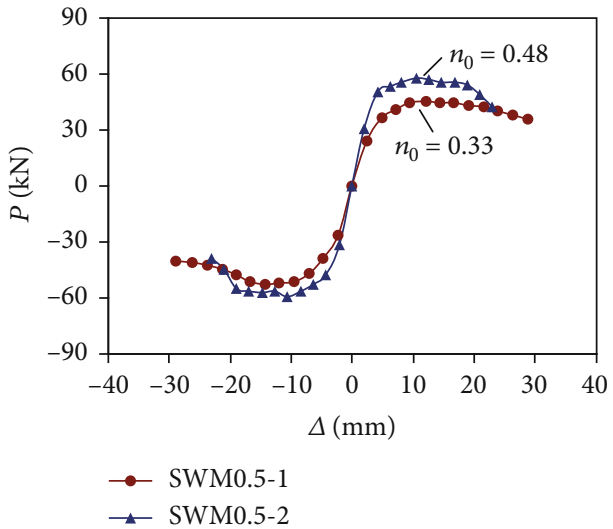

(d)

FIGURE 7: Skeleton curves of columns. 
TABLE 3: Main test results of columns.

\begin{tabular}{lcccc}
\hline Column & $\begin{array}{c}\text { Axial } \\
\text { load } \\
\text { ratio } \\
n_{0}\end{array}$ & $\begin{array}{c}\text { Ultimate } \\
\text { bearing } \\
\text { capacity } \\
(\mathrm{kN})\end{array}$ & $\begin{array}{c}\text { Displacement } \\
\text { ductility } \mu_{\Delta}\end{array}$ & $\begin{array}{c}\text { Total energy } \\
\text { dissipation } \\
(\mathrm{J}) / \text { numbers of } \\
\text { hysteresis loops }\end{array}$ \\
\hline O & 0.33 & 34.3 & 3.9 & $6840.1 / 25$ \\
SM-1 & 0.33 & 39.1 & 4.9 & $7838.4 / 31$ \\
SM-2 & 0.48 & 70.8 & 4.3 & $10962.3 / 30$ \\
SWM1-1 & 0.33 & 40.8 & 5.2 & $12647.0 / 33$ \\
SWM1-2 & 0.48 & 76.4 & 4.7 & $14973.6 / 35$ \\
SWM2-1 & 0.33 & 42.8 & 5.7 & $13765.7 / 33$ \\
SWM2-2 & 0.48 & 81.9 & 5.5 & $18579.4 / 39$ \\
SWM0.5- & 0.33 & 43.6 & 6.1 & $15200.4 / 37$ \\
1 & & & & \\
SWM0.5- & 0.48 & 59.7 & 5.4 & $16352.7 / 35$ \\
2 & & & &
\end{tabular}

For column SM-2, after repeated lateral loading, horizontal bending cracks appeared at the bottom of the column. When the loading displacement at the top of the column increased to $4 \triangle_{0}$, vertical cracks along the longitudinal reinforcement appeared at the bottom of the column. The possible reasons for this phenomenon are as follows: (1) the protective layer of repair mortar is too thin $(9 \mathrm{~mm})$; (2) the bonding force between interfaces is low; (3) the reinforcement dispersion of steel bar mat is low, which cannot effectively restrain the repair mortar. When the displacement at the top of the column reached $13.2 \mathrm{~mm}$, the bearing capacity of the column began to decrease. Finally, the longitudinal bar of the column was bent, the concrete on the surface of the column peeled off in large area, and the test was stopped. The failure pattern of column SM-2 is shown in Figure 5(b).

For column SWM1-2, no visible cracks appeared on the surface of the column during the force control loading stage. After entering the displacement control loading stage, horizontal bending cracks gradually appeared near the footing of the column. With the further increase of loading displacement at the top of the column, the cracks on the bottom surface of the column become more and more dense by interlacing. In the later stage of test, the repair mortar on the four sides of the column bottom fell off in small pieces. The possible reasons for this phenomenon are as follows: (1) the steel wire mesh has excellent crack control ability; (2) the bonding and protection of the steel wire mesh mortar layer have been fully exerted. When the column was damaged nearby, a groaning noise could be heard inside the column. Finally, when the loading displacement at the top of the column reached $25.1 \mathrm{~mm}$, the column was obviously bent and damaged, and the test was stopped. The failure pattern of column SM-2 is shown in Figure 5(c).

3.2. Hysteresis Loops and Skeleton Curves. The hysteresis loops obtained from this test are shown in Figure 6. The strengthening method has a significant effect on the hysteresis loops. For example, the hysteresis loop of the column SWM2-2 has a stable and plump spindle shape with a large number of cycles, indicating that the seismic performance of the column had been significantly improved. In this test, the hysteresis loop of forward loading is slightly different from that of reverse loading for each column. This difference is related to the initial state of the column before the lateral load was applied, the difference in the mechanical properties of the longitudinal bar, and the construction quality.

The skeleton curves obtained from this test are shown in Figure 7. The axial load ratio has a significant effect on the skeleton curves. When the axial load ratio increased from 0.33 to 0.48 , the skeleton curve of the corresponding column became unstable. It can be seen from Figure 7 that the high axial force ratio makes the descending branch of the column skeleton curve steeper, indicating that the strength of the column degrades faster. It can be seen from Figure 7 that the seismic bearing capacity and initial stiffness of the column increase as the axial load ratio increases.

3.3. Bearing Capacity and Ductility. The ultimate bearing capacity of each column is listed in Table 3. Based on Table 3, it can be seen that effective strengthening methods can improve the seismic bearing capacity of columns. When the axial force ratio $(n=0.33)$ is the same, the ultimate bearing capacity of column SM-1 and column SWM2-1 is higher than that of column O by $13.9 \%$ and $24.8 \%$, respectively. It should also be noted that the ultimate bearing capacity of column SWM2-1 is $2 \mathrm{kN}$ larger than that of column SWM1-1, indicating that increasing the reinforcement ratio has a certain effect on improving the seismic performance of the column.

The displacement ductility factor $\left(\mu_{\Delta}\right)$ can be used to express the ductility characteristics of the column, which is defined as the ratio of the ultimate displacement of the column to the yield displacement $[12,13]$. The displacement ductility factors of all columns are listed in Table 3. As can be seen from Table 3, the displacement ductility factor of column SWM2-1 is higher than that of column SM-1 by $16 \%$. This enhancement can be attributed to the fact that the wire mesh with larger specific surface area can improve the dispersion of reinforcement, thus playing an active role in preventing the concrete protective layer of the column from falling off. As can be seen from Table 3, when the axial force ratio of the column is increased from 0.33 to 0.48 and other test parameters remain unchanged, it can be found that the displacement ductility factor of the column is significantly reduced. This is because the ultimate deformation capacity of the column becomes worse as the axial force applied to the column increases.

3.4. Energy Dissipation. The energy dissipated by the column is defined as the area surrounded by the measured hysteresis loop during a loading cycle $[14,15]$. The area of each hysteresis loop is added up to be the total energy 


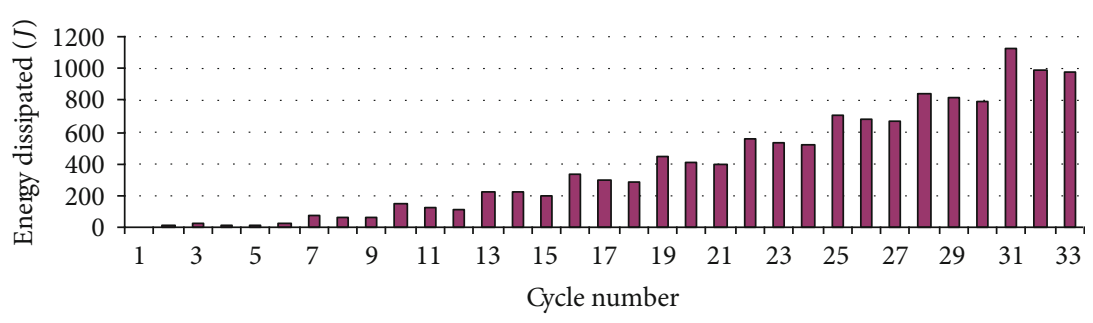

FIgURE 8: Energy dissipation of column SWM1-1.

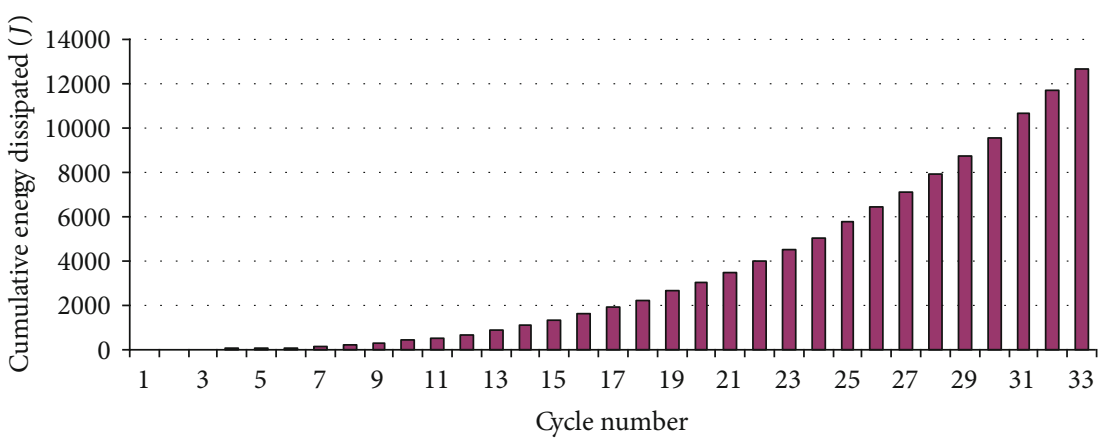

FIgURE 9: Cumulative energy dissipation of column SWM1-1.

dissipated by the column in the test. The energy dissipated in a single cycle and the accumulated energy dissipated by the column SWM1-1 are shown in Figures 8 and 9, respectively. Figure 8 shows that in the three cycles of loading at the same level, the energy dissipated by the column gradually decreases. The total energy dissipated by all columns is listed in Table 3 . The reinforcement ratio of column SWM1-1 is only higher than that of column SM-1 by $0.201 \%$, and the total dissipated energy of column SWM1-1 is higher than that of column SM-1 by $61.4 \%$. This indicates that SWM-strengthened columns can withstand seismic action more effectively and enhance the reliability of the structure.

3.5. Strength Degradation. In the test, the strength of the column began to decrease gradually after its bearing capacity reached its peak. Generally, the strength degradation coefficient $(\zeta)$ is used to measure the speed of the strength degradation of the column. As for the strength degradation coefficient, it is defined as the ratio of the $i$ th cyclic peak load to the first cyclic peak load under displacement loading of the same level [16-20]. When $i=3$, the $\zeta$ of each column is shown in Figure 10. It can be observed from Figure 10 that the strength degradation of the column increases with the increase of axial load ratio. This is because the compressive strain on the section of the column increases as the axial load ratio increases, resulting in the column being damaged.

3.6. Stiffness Degradation. When the axial load ratio of the column is equal to 0.33 and 0.48 , the secant stiffness of the column is shown in Figures 11(a) and 11(b), respec- tively. Under the action of cyclic loading, stiffness degradation occurred in all columns, which showed fast degradation in the early stage and slow degradation in the later stage. By comparing Figures 11(a) and 11(b), it is found that the initial stiffness of the column under the action of high axial load ratio is higher, but the stiffness degrades faster. Although the stiffness of the strengthened column increases at different stages, the effect of the strengthening method on the stiffness degradation rate is not obvious.

3.7. Influence of the Layers of Wire Mesh. In this test, the layers of wire mesh are also taken as a research parameter. The initial results show that the seismic capability of the column is enhanced after increasing the layers of wire mesh, but the specific quantitative relationship is not concluded in this test, which needs to be further studied.

\section{Conclusions}

(1) In this test, bending failure mode occurred in all columns, and cracks on the bottom surface of SWM-strengthened columns showed multiple and dense distribution, and no concrete with large area was seen to fall off at the late stage of loading

(2) After strengthened with SWM, the seismic performance of the column is effectively improved, which is manifested in the increase of ultimate bearing capacity, ductile displacement, and total dissipated energy, indicating that the strengthening method can be applied in engineering practice 

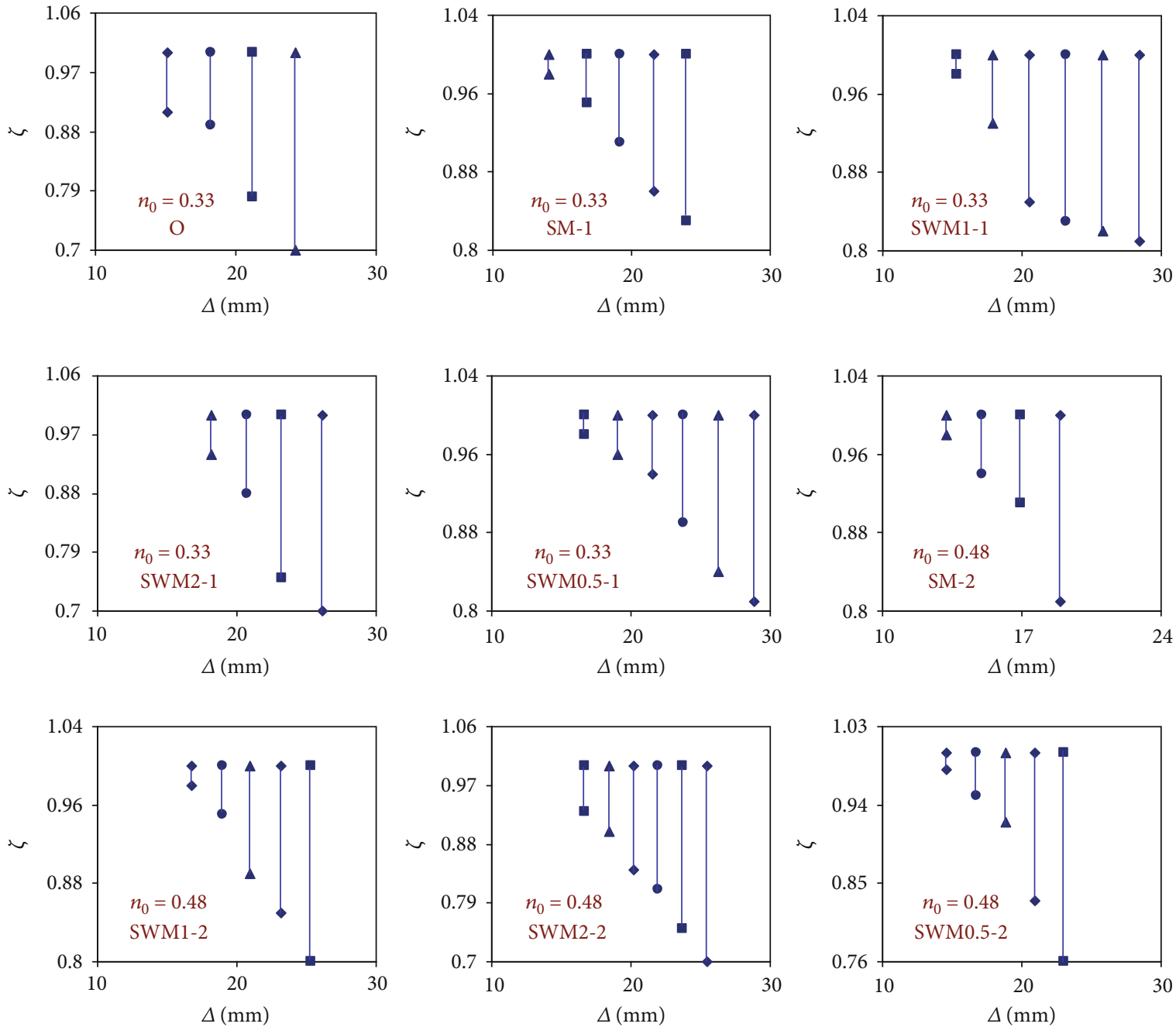

Figure 10: Strength degradation coefficient $\zeta_{i}(i=3)$.

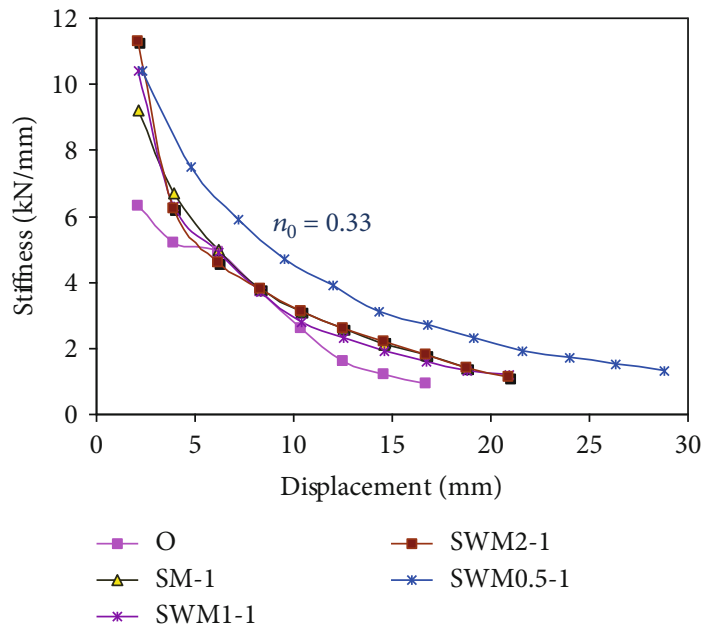

(a)

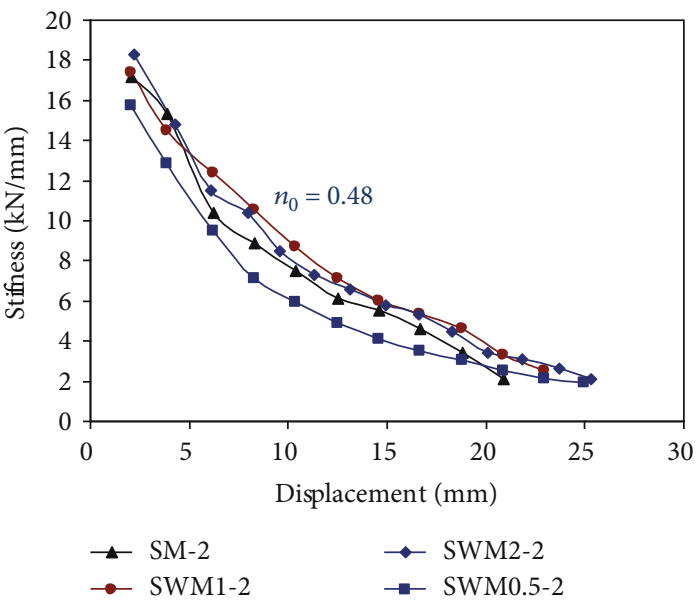

(b)

Figure 11: Stiffness degradation of columns. 
(3) Axial load ratio is a key parameter that affects the seismic capacity of a column. With the increase of axial load ratio, the ultimate bearing capacity and initial stiffness of the column increase, the ductile displacement decreases, and the strength degradation and stiffness degradation accelerate

\section{Data Availability}

The data are available and explained in this article; readers can access the data supporting the conclusions of this study.

\section{Disclosure}

I would like to declare on behalf of my co-authors that the work described is an original research and has not been previously published.

\section{Conflicts of Interest}

Authors declare no conflict of interest.

\section{Authors' Contributions}

The manuscript is approved by all authors for publication.

\section{Acknowledgments}

The authors gratefully acknowledge the funding provided by the Technology Top Talent Support Project of Guizhou Provincial Education Department under Item No. [2017]098, the Guizhou Provincial Science and Technology Program under Item No. [2017]1062, and the Joint Fund of the Guizhou Provincial Science and Technology under Item No. [2015]7592.

\section{References}

[1] ACI 318-2008/ACI 318R-08, Building Code Requirements for Reinforced Concrete and Commentary, American Concrete Institute, Farmington Hills, MI, 2008.

[2] Z. Li, H. Liu, Z. Dun, L. Ren, and J. Fang, "Grouting effect on rock fracture using shear and seepage assessment," Construction and Building Materials, vol. 242, p. 118131, 2020.

[3] B. Kondraivendhan and B. Pradhan, "Effect of ferrocement confinement on behaviour of concrete," Construction and Building Materials, vol. 23, no. 3, pp. 1218-1222, 2009.

[4] Z. Li, H. Zhou, D. Hu, and C. Zhang, "Yield criterion for rocklike geomaterials based on strain energy and CMP model," International Journal of Geomechanics, vol. 20, no. 3, article 04020013, 2020.

[5] X. Zhang, Y. Wu, E. Zhai, and P. Ye, "Coupling analysis of the heat-water dynamics and frozen depth in a seasonally frozen zone," Journal of Hydrology, p. 125603, 2020.

[6] Z. Li, S. Liu, W. Ren, J. Fang, Q. Zhu, and Z. Dun, "Multiscale laboratory study and numerical analysis of water-weakening effect on shale," Advances in Materials Science and Engineering, vol. 2020, Article ID 5263431, 14 pages, 2020.

[7] C. Zhu, X. Xu, X. Wang et al., "Experimental investigation on nonlinear flow anisotropy behavior in fracture media," Geofluids, vol. 2019, no. 9, Article ID 5874849, 9 pages, 2019.
[8] X. Wang, C. Liu, S. Chen, L. Chen, K. Li, and N. Liu, "Impact of coal sector's de-capacity policy on coal price," Applied Energy, vol. 265, p. 114802, 2020.

[9] S. P. Shang, L. M. Jiang, and M. X. Zhang, "Experimental investigation into the strengthening of eccentric compression $\mathrm{RC}$ column using composite mortar laminate reinforced with mesh reinforcement," Journal of Building Structures, vol. 26, no. 2, pp. 18-25, 2005.

[10] ACI Committee 318, Building Code Requirements for Structural Concrete (ACI 318-05), American Concrete Institute, Farmington Hills (MI), 2005.

[11] China National Standard, Code for Design of Concrete Structures; GB 50010-2010, China National Standard, Beijing, China, 2010.

[12] G. J. Xiong, X. Y. Wu, F. F. Li, and Z. Yan, "Load carrying capacity and ductility of circular concrete columns confined by ferrocement including steel bars," Construction and Building Materials, vol. 25, no. 5, pp. 2263-2268, 2011.

[13] H. Saadatmanesh, M. R. Ehsani, and L. Jin, "Repair of earthquake-damaged RC columns with FRP wraps," ACI Structural Journal, vol. 2, no. 94, pp. 206-214, 1997.

[14] M. A. Hussain and R. G. Driver, "Experimental study on the seismic performance of externally confined reinforced concrete columns," in 13th World Conference on Earthquake Engineering, Vancouver, B.C., Canada, August 2004.

[15] Y. A. Al-Salloum, N. A. Siddiqui, and H. M. Elsanadedy, “Textile-reinforced mortar versus FRP as strengthening material for seismically deficient RC beam-column joints," Journal of Composites for Construction, vol. 6, no. 12, pp. 920-933, 2011.

[16] J. Niwa, K. Shakya, K. Matsumoto, and K. Watanabe, "Experimental study on the possibility of using steel fiber-reinforced concrete to reduce conventional rebars in beam-column joints," Journal of Materials in Civil Engineering, vol. 24, no. 12, pp. 1461-1473, 2012.

[17] C. Zhu, Z. H. Yan, Y. Lin et al., "Design and application of a monitoring system for a deep railway foundation pit project," IEEE Access, vol. 7, no. 1, pp. 107591-107601, 2019.

[18] Q. Meng, H. Wang, M. Cai, W. Xu, X. Zhuang, and T. Rabczuk, "Three-dimensional mesoscale computational modeling of soil-rock mixtures with concave particles," Engineering Geology, vol. 277, article 105802, 2020.

[19] X. J. Yang, J. M.* Wang, D. G. Hou, C. Zhu, and M. C. He, "Effect of dry-wet cycling on the mechanical properties of rocks: a laboratory-scale experimental study," Processes, vol. 6, no. 10, p. 199, 2018.

[20] L. L. Yang, W. Y. Xu, Q. X. Meng, and R. B. Wang, "Investigation on jointed rock strength based on fractal theory," Journal of Central South University, vol. 24, no. 7, pp. 1619-1626, 2017. 